\title{
Response of the Christchurch Water Distribution System to the 22 February 2011 Earthquake
}

\author{
D. Bouziou ${ }^{1, \uparrow *}$ and T.D. O'Rourke ${ }^{2}$ \\ ${ }^{1}$ Edafos Engineering Consultants S.A., Yperidou Str. 9, Athens 10558, Greece \\ ${ }^{2}$ School of Civil and Environmental Engineering, Cornell University, Ithaca NY 14853, USA
}

\begin{abstract}
The effects of transient and permanent ground deformations during the 22 February 2011 earthquake on the Christchurch water distribution system are investigated through geospatial analysis with the most detailed and accurate databases currently available. Using the most recent repair records, ground motion records, high resolution Light Detection and Ranging (LiDAR) data collected before and after the earthquake, and improved screening criteria, repair rates, expressed as repairs $/ \mathrm{km}$, for different types of pipeline are correlated with 1) peak ground velocity outside liquefaction areas, and 2) differential ground surface lateral and vertical movements in liquefaction areas. The substantial influence of LiDAR resolution on the relationship between pipeline damage and lateral ground strain indicates sensitivity of repair regressions to the degree of data resolution. Repair regressions of different pipelines show that polyvinyl chloride pipelines are markedly more resilient to earthquake effects than other types of segmental pipelines in the Christchurch system. The analytical process is described in detail for assistance in future investigations with data sets of similar size and complexity.
\end{abstract}

KEY WORDS: geospatial analysis; pipelines; earthquake; Christchurch; LiDAR; repair regressions

\section{INTRODUCTION}

The 22 February 2011 earthquake (Moment Magnitude, $M_{w}=6.2$ ) was the most severe seismic event during the 2010-2011 Canterbury Earthquake Sequence (CES) that caused unprecedented damage in the city of Christchurch and the largest number of fatalities since the 1931 Hawkes Bay (Napier) earthquake. The 22 February 2011 earthquake was caused by a local fault approximately $5 \mathrm{~km}$ south-east of the Christchurch Central Business District (CBD) which

\footnotetext{
"Correspondence to: Dimitra Bouziou, Edafos Engineering Consultants S.A., Yperidou 9, Athens 10558, Greece

${ }^{\dagger}$ E-mail: db552@cornell.edu

Abbreviations:

LiDAR: Light Detection and Ranging

GMPGV: Geometric Mean Peak Ground Velocity

PGD: Permanent Ground Deformation

TGD: Transient Ground Deformation
} 
produced strong to very strong ground shaking within Christchurch [1]. The water distribution system in Christchurch was severely affected by ground shaking and widespread liquefaction that took place over $96 \mathrm{~km}^{2}(66 \%)$ of the Christchurch area.

Systematic mapping and recording of damage in the water distribution system, as well as observations and measurements of transient ground motion and permanent ground surface movements, resulted in data sets associated with the CES that are unique in size and detail. The geospatial data sets that are used in this study include high resolution Light Detection and Ranging (LiDAR) surveys before and after the 22 February earthquake, maps of areas of liquefaction interpreted from aerial photography and lateral spreading observations, ground motion records from 40 stations, and detailed repair records of thousands of $\mathrm{km}$ of underground pipelines in the water distribution system.

This paper provides significant updates to and expansion of investigations by O'Rourke et al. [2] for analysis of underground pipeline performance during the CES. The present study uses the most recent and improved water distribution network repair records provided by the Stronger Christchurch Infrastructure Rebuild Team (SCIRT). High resolution LiDAR lateral movements on 4-m spacing were acquired for this study and represent a significantly higher degree of resolution than those associated with 56-m spacing, which originally were released by the Canterbury Earthquake Recovery Authority (CERA) [3] and were used in the previous study. Moreover, refinements in the geostatistical processing of ground motion data to include the effects of anisotropy are used in this work to develop correlations between pipeline damage and peak ground velocity (PGV).

\section{GIS DATABASE}

Figure 1 shows the water distribution system in Christchurch City and Lyttelton Harbor superimposed on areas of liquefaction effects and pipeline repair locations associated with the 22 Feb. 2011 earthquake. Geospatial data for the 22 Feb. 2011 earthquake include approximately $1700 \mathrm{~km}$ of water mains and trunk lines, ranging from 75 to $600 \mathrm{~mm}$ in diameter, with internal pressure of about $100 \mathrm{kPa}$. It does not include repairs to smaller diameter submains and customer service laterals. The water distribution system spatial dataset developed by SCIRT, and sourced originally from the Christchurch City Council (CCC), provides the most complete picture of the system as of 4 Sept. 2010 and includes information about the type, diameter, material, length, and year of installation for each individual pipe in the network [4]. It also includes information on continuous daily repair records for re-establishment of services between the period from February 23, 2011 to March 11, 2013, after the occurrence of the 13 June 2011 and 23 December 2011 earthquakes and numerous aftershocks. Similar to the study by O'Rourke et al. [2], water distribution system repair records in the latest data set dating from February 23, 2011 to April 15, 2011 were related to the 22 Feb. 2011 earthquake and were used in this study.

The areas of liquefaction effects presented in Figure 1 were derived from maps of observed liquefaction effects that were documented through aerial photography and site observations, and are available through the Canterbury Geotechnical Database [5]. Observed liquefaction effects include sand ejecta, ground cracking, lateral spreading and differential surface settlement. The 
areas of observed liquefaction were only defined by visible surface features and, therefore, they were expanded to account for a zone of influence at their perimeter that affects underground pipelines. The zone of influence of underground pipeline damage was taken as $125 \mathrm{~m}$, which is approximately one-half a typical street length in a residential neighborhood and is consistent with the distance that significant pullout forces can be transmitted longitudinally along underground pipelines [6]. These areas are described in this paper as the areas of liquefaction effects.

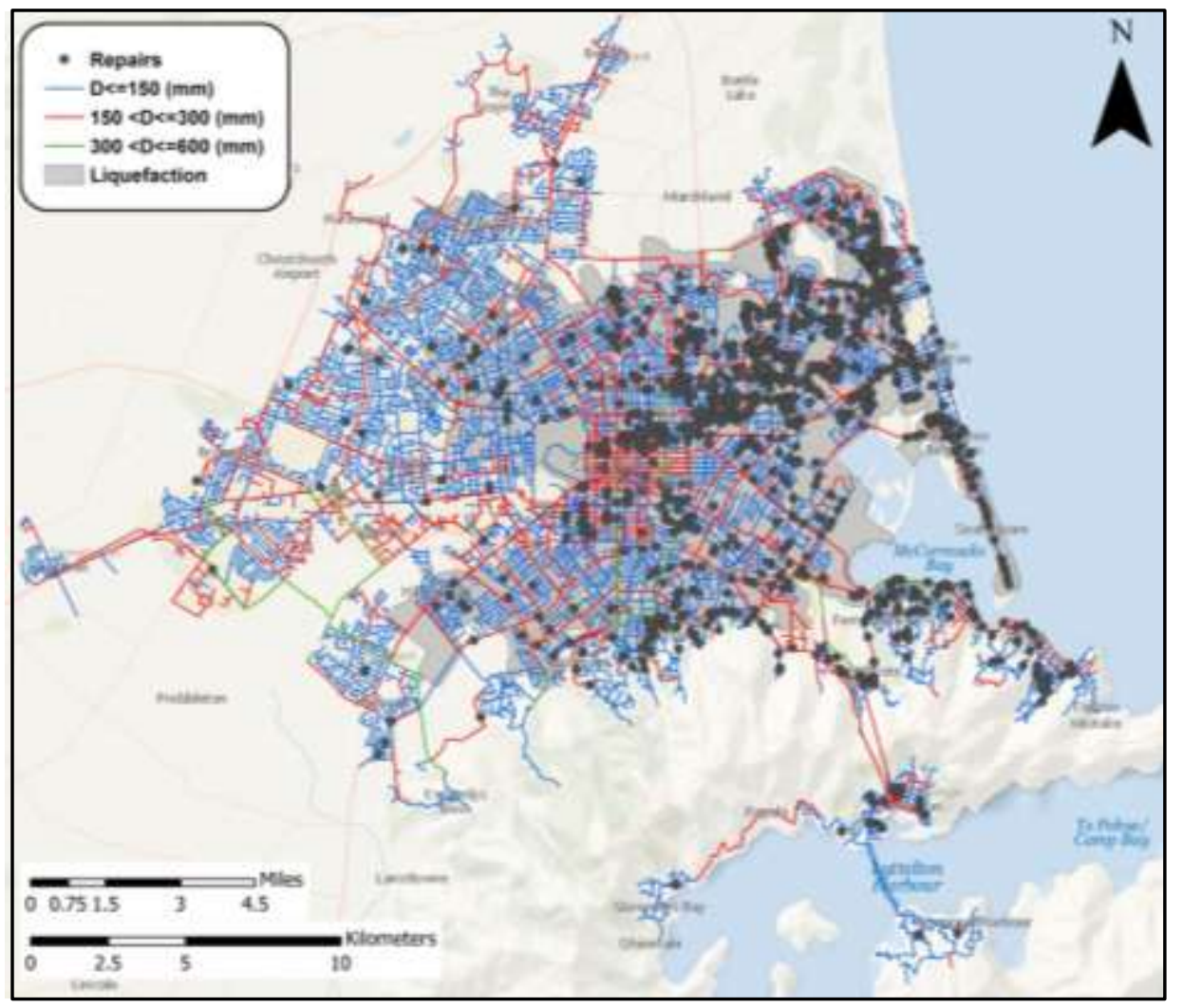

Figure 1. Map of Christchurch water distribution system during the $22 \mathrm{Feb} .2011$ earthquake.

Ground motion records related to the 22 Feb. 2011 earthquake from 40 stations in the Christchurch area were selected for spatial analysis [7]. The selected records were fully processed by GNS Science [8] to provide acceleration, velocity, and displacement time histories and response spectra. The processed data from GNS Science are derived using a filter with corner frequencies of $25 \mathrm{~Hz}$ and $0.25 \mathrm{~Hz}$, meaning that the ground motions are screened to focus on periods between 0.04 and $4 \mathrm{sec}$. The geometric mean peak ground velocity (GMPGV) was used as a metric in pipeline repair regressions in areas affected by transient ground deformations (TGD). Peak ground velocity has been shown in previous studies to provide the most robust regressions related to pipeline damage (e.g., [9]). GMPGV was calculated for each station as the mean of the natural logs of the two horizontal orthogonal PGV components recorded at the station and obtained through GNS Science.

Airborne Light Detection and Ranging (LiDAR) data were obtained by AAM Brisbane (AAM) and New Zealand Aerial Mapping (NZAM) before and after each of the main seismic events 
during the CES, and pairs of these data were combined by GNS Science (accessed June 2013), under contract with Tonkin \& Taylor Pty Ltd (T\&T), Christchurch, New Zealand, to determine horizontal and vertical ground movements. Vertical ground movements were developed at 5-m spacing, whereas horizontal movements at 4-m and 56-m spacing. The NZAM LiDAR give a fundamental vertical accuracy of $\pm 10 \mathrm{~cm}$ for areas of open ground with hard surfaces, and the AAM LiDAR give a fundamental vertical accuracy of \pm 7 to $\pm 15 \mathrm{~cm}$ [10]. The AAM LiDAR horizontal accuracy, compared to land survey measurements supplied by the Christchurch City Council (CCC), Land Information New Zealand (LINZ) and Environment Canterbury, is 40 to $55 \mathrm{~cm}$ [10]. The vertical and horizontal ground surface movements developed by pairs of LiDAR data sets collected before and after the 22 February 2011 earthquake were used to develop grids of differential vertical and horizontal ground movement.

\section{SPATIAL ANALYSIS OF PIPELINE DAMAGE}

Pipeline repair rates (RRs), expressed as repairs/km, were evaluated through spatial analysis with respect to 1) areas unaffected by liquefaction effects where TGD is likely to be the primary cause of damage, and 2) areas affected by liquefaction effects, where PGD is likely to be the primary cause of damage. Using the data sets described above, the spatial distribution of damage in the water distribution system during the 22 Feb. 2011 earthquake was quantified and is summarized in Table 1. The table provides information pertaining to pipeline length, repairs, and RRs for asbestos cement (AC), cast iron (CI), polyvinyl chloride (PVC), and modified polyvinyl chloride (MPVC) pipelines in the water distribution system, including locations inside and outside areas of liquefaction effects. The category of "other" includes pipe types that were individually present in the network in quantities too small to provide statistically robust correlations. The information provided in Table 1 is derived using the most accurate and complete data set of pipeline repairs that were obtained through SCIRT in March, 2013.

Column 4 in Table 1 shows the RRs for each pipe type as the ratio of the total number of repairs for each pipe type to the total length of each pipe type. The percentage of repairs within the areas of liquefaction effects for each pipe type with respect to the total number of repairs recorded for each pipe type is presented in column 5. Similarly, the percentage pipeline within the areas of liquefaction effects for each pipe type with respect to the total length of each pipe type is presented in column 6 . Column 7 shows the percentage of pipelines that were damaged within the areas of liquefaction effects for each pipe type with respect to the total length of each pipe type. In a similar manner, column 8 shows the percentage of pipelines that were damaged outside the areas of liquefaction effects for each pipe type with respect to the total length of each pipe type. Finally, column 9 shows the average RR for each pipe type as the ratio of repairs of each pipe type within the areas of liquefaction effects to pipeline length of each pipe type within the areas of liquefaction effects, and, similarly, column 10 shows the average RR for each pipe type as the ratio of repairs of each pipe type outside the areas of liquefaction effects to pipeline length of each pipe type outside the areas of liquefaction effects.

The use of RR as a normalized indicator of pipeline damage allows for comparison of the vulnerability of different pipe types relative to their total length in the water distribution network. As shown in Table 1, the RRs for AC and CI pipes are similar and approximately 3 to 4 times 
greater than PVC pipe RRs, and 6 to 15 times greater than MPVC pipe RRs. The average RRs inside the liquefied areas are at least 4 times greater than RRs in areas without liquefaction effects for all pipe types. Table 1 also provides information about the distribution of repairs and pipelines inside and outside the areas of liquefaction effects. More than $80 \%$ of repairs for each pipe type are located inside the areas of liquefaction effects, whereas the percentage of pipelines within the areas of liquefaction effects for each pipe type ranges between $33 \%$ and $83 \%$. The aforementioned remarks verify that pipeline damage during the 22 February 2011 earthquake was associated primarily with PGD effects caused by liquefaction. The percentage of damaged pipelines inside and outside the areas of liquefaction effects is also used in Table 1 as an indicator of damage and shows that pipeline damage was mostly concentrated inside the liquefied zone. As shown in Table 1, AC and CI pipes were most severely affected by the 22 Feb. 2011 earthquake, whereas PVC and MPVC pipes performed significantly better.

Table 1. Statistics of water main and trunk line pipeline repairs and repair rates in both liquefaction and non-liquefaction areas for different water pipe types.

\begin{tabular}{|c|c|c|c|c|c|c|c|c|c|c|}
\hline & 1 & 2 & 3 & 4 & 5 & 6 & 7 & 8 & 9 & 10 \\
\hline & $\begin{array}{c}\text { Pipe } \\
\text { Materia } \\
1\end{array}$ & $\begin{array}{c}\text { Pipe } \\
\text { Length } \\
(\mathrm{km})\end{array}$ & $\begin{array}{c}\text { Repair } \\
\text { s }\end{array}$ & $\begin{array}{c}\text { Overall } \\
\text { Averag } \\
\text { e RR }\end{array}$ & $\begin{array}{c}\% \\
\text { Repair } \\
\mathrm{s} \text { in } \\
\text { LIQ }^{1} \\
\text { areas }\end{array}$ & $\begin{array}{c}\% \\
\text { Pipeline } \\
\text { in LIQ } \\
\text { areas }\end{array}$ & $\begin{array}{c}\% \\
\text { Damage } \\
\mathrm{d} \\
\text { Pipeline } \\
\text { in } \mathrm{LIQ}^{1} \\
\text { areas }\end{array}$ & $\begin{array}{c}\% \\
\text { Damage } \\
\mathrm{d} \\
\text { Pipeline } \\
\text { in Non } \\
\text { LIQ }^{1} \\
\text { areas } \\
\end{array}$ & $\begin{array}{c}\text { Average } \\
\mathrm{RR}^{2} \text { in } \\
\mathrm{LIQ}^{1} \\
\text { areas }\end{array}$ & $\begin{array}{c}\text { Average } \\
\mathrm{RR}^{2} \text { in } \\
\text { Non } \\
\mathrm{LIQ}^{1} \\
\text { areas }\end{array}$ \\
\hline \multirow{6}{*}{$\begin{array}{c}22 \\
\text { February } \\
2011\end{array}$} & $\mathrm{AC}$ & 867.2 & 1024 & 1.18 & $85 \%$ & $47 \%$ & $16 \%$ & $3 \%$ & 2.15 & 0.33 \\
\hline & $\mathrm{CI}$ & 194.4 & 255 & 1.31 & $89 \%$ & $67 \%$ & $14 \%$ & $3 \%$ & 1.73 & 0.44 \\
\hline & $\mathrm{PVC}$ & 213.6 & 68 & 0.32 & $93 \%$ & $52 \%$ & $5 \%$ & $1 \%$ & 0.56 & 0.05 \\
\hline & MPVC & 149.7 & 13 & 0.09 & $100 \%$ & $33 \%$ & $2 \%$ & $0 \%$ & 0.27 & 0.00 \\
\hline & Other & 305.4 & 142 & 0.47 & $83 \%$ & $83 \%$ & $4 \%$ & $4 \%$ & 0.46 & 0.47 \\
\hline & Total & 1730.3 & 1502 & 0.87 & $86 \%$ & $55 \%$ & $11 \%$ & $2 \%$ & 1.36 & 0.27 \\
\hline
\end{tabular}

${ }^{1}$ LIQ: Areas of liquefaction effects

${ }^{2}$ RR: Repair Rate

\section{SCREENING CRITERIA}

The screening criteria developed by O'Rourke et al. [2] were used during the regression analysis of pipeline damage to ensure fidelity of the RR correlations. As recommended by previous researchers [11], it was assumed that pipeline damage follows a Poisson distribution where

$$
(1-\alpha) p \leq(R R) x \leq(1+a) p
$$

in which $p$ is the actual number of repairs, $R R$ is repair rate, $\alpha$ is a fraction of the actual number of repairs, and $\mathrm{x}$ is the sampling length. For a Poisson distribution the mean is $\mu=(\mathrm{RR}) \mathrm{x}$ and the standard deviation is $\sigma=[(\mathrm{RR}) \mathrm{x}]^{1 / 2}$. 
The confidence level corresponding to the sampled number of repairs falling within $\pm \alpha$ of the actual repairs can be estimated by recognizing that the sampled repairs follow a normal distribution in accordance with the central limit theorem. For a confidence level interval, $\beta_{c}$, and standard normal deviate, $\varphi^{-1}\left(\beta_{\mathrm{c}}\right)$, the lower and upper bounds of Equation 1 are

$$
\mu \pm \varphi^{-1}\left(\beta_{c}\right) \sigma=(1 \pm \alpha) p
$$

Combining Equations 1 and 2 with $\mathrm{p}=(\mathrm{RR}) \mathrm{x}$ results in

$$
x \geq^{\left[\varphi^{-1}\left(\beta_{c}\right)\right]^{2}} / \alpha^{2}(R R)
$$

Equation 3 provides the minimum sampling length, $x$, needed for a confidence level, $\beta_{c}$, that the actual number of repairs falls within $\pm \alpha$ of the mean value (RR)x. The screening criterion presented in Equation 3 allows for sampling and data selection to be administered by choosing $\beta_{\mathrm{c}}$ and $\alpha$. In the present study, $\alpha$ was equal to $50 \%$ and a relatively high confidence interval of $\geq$ $90 \%$ was applied in most cases. As presented in the following sections, in some cases the confidence interval was reduced to produce additional RR data and extend ground deformation levels in RR correlations over a broader range.

\section{RR CORRELATIONS WITH GMPGV}

The performance of the Christchurch water distribution system in areas affected by TGD during the 22 February 2011 earthquake was evaluated through correlations of pipeline damage with earthquake ground motions. Figure 2 presents the flow chart of the spatial analysis steps that were followed in developing RR correlations with GMPGV. The spatial distribution of GMPGV was interpolated using ground motions recorded at 40 stations during the 22 February 2011 earthquake. The peak ground velocity (PGV) horizontal orthogonal components that were processed by GNS Science [3] were used to calculate the GMPGV sample values that were introduced in the geostatistical model. The spatial interpolation technique employs an ordinary kriging model with a spherical variogram similar to the study by Jeon and O'Rourke [9]. The spherical variogram used in this study accounts for anisotropy to incorporate the influence of direction dependency as a result of forward directivity and strong basin edge effects that have been reported by Bradley and Cubrinovski [12] for the 22 February 2011 earthquake.

The areas of observed liquefaction were imported in ArcMap 10.1 [13] and were subsequently expanded by $125 \mathrm{~m}$ using the "buffer" tool to account for a zone of influence at the perimeter of the liquefaction areas that affects underground pipelines. Pipelines and repairs that were projected in ArcMap 10.1 [13] and were located inside the expanded liquefaction areas were excluded from the analytical process for PGV using the "erase" tool based on the assumption that they were associated with PGD effects. Pipelines affected by landslides and rock falls during the 22 February 2011 earthquake were also removed in a similar manner assuming that pipelines 
at elevation above $50 \mathrm{~m}$ in the Port Hills were primarily affected by landslide- and rockfall-

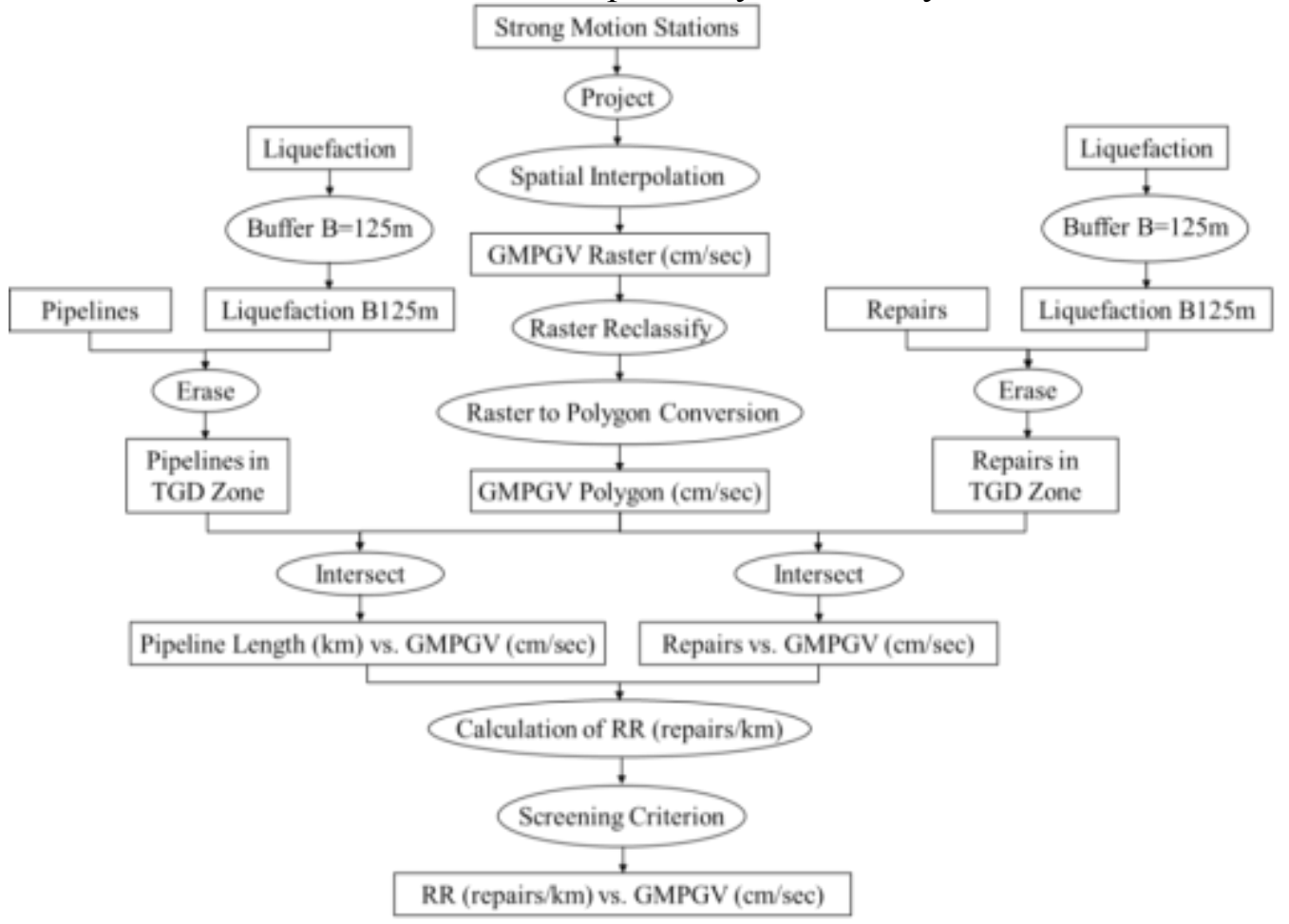

Figure 2. Flow chart for RR correlations with GMPGV (Rectangles represent input/output data sets and ovals represent processes/tools).

related PGD. Pipelines and repairs outside the expanded areas of observed liquefaction and at elevations below $50 \mathrm{~m}$ were spatially intersected by the geostatistically-determined GMPGV surface layer using the "intersect" tool in ArcMap 10.1 [13]. Using the spatially located pipelines and repairs, the repair rate (RR) for a given interval of GMPGV was calculated by dividing the number of repairs for a particular type of pipeline by the kilometers of that pipeline type within a contour interval of $10 \mathrm{~cm} / \mathrm{s}$. The resulting RR was then associated with a value of GMPGV and was used as a single data point in RR correlations. The screening criteria previously discussed were applied to produce RR vs GMPGV correlations using appropriate confidence intervals.

Figures $3 \mathrm{a}$ and $3 \mathrm{~b}$ show the areas of liquefaction effects, water distribution pipelines, repairs outside liquefied areas, and $10 \mathrm{~cm} / \mathrm{sec}$ contours of GMPGV for the 22 Feb. 2011 earthquake, pertaining to $\mathrm{AC}$ and $\mathrm{CI}$ distribution mains, respectively. Correlations of RR vs GMPGV were not developed for PVC pipelines due to insufficient number of PVC pipeline repairs even after considering lower confidence levels in the screening process. Ground motion directionality in the northwest direction is reflected in the contours of GMPGV and is in good agreement with the remarks made by Bradley and Cubrinovski [12] for forward directivity effects in the fault normal component that are manifested as large ground velocities.

The results of regression analysis for RR vs GMPGV for AC and CI pipelines are presented in Figures $4 \mathrm{a}$ and $4 \mathrm{~b}$, respectively. The RRs for AC pipelines and various GMPGV values for the 22 February 2011 earthquake were combined with similar data reported by Jeon [14] for AC pipelines damaged during the 1994 Northridge earthquake. Similarly, the RR vs GMPGV data 
points for CI pipelines for the 22 February 2011 earthquake were combined with historical data
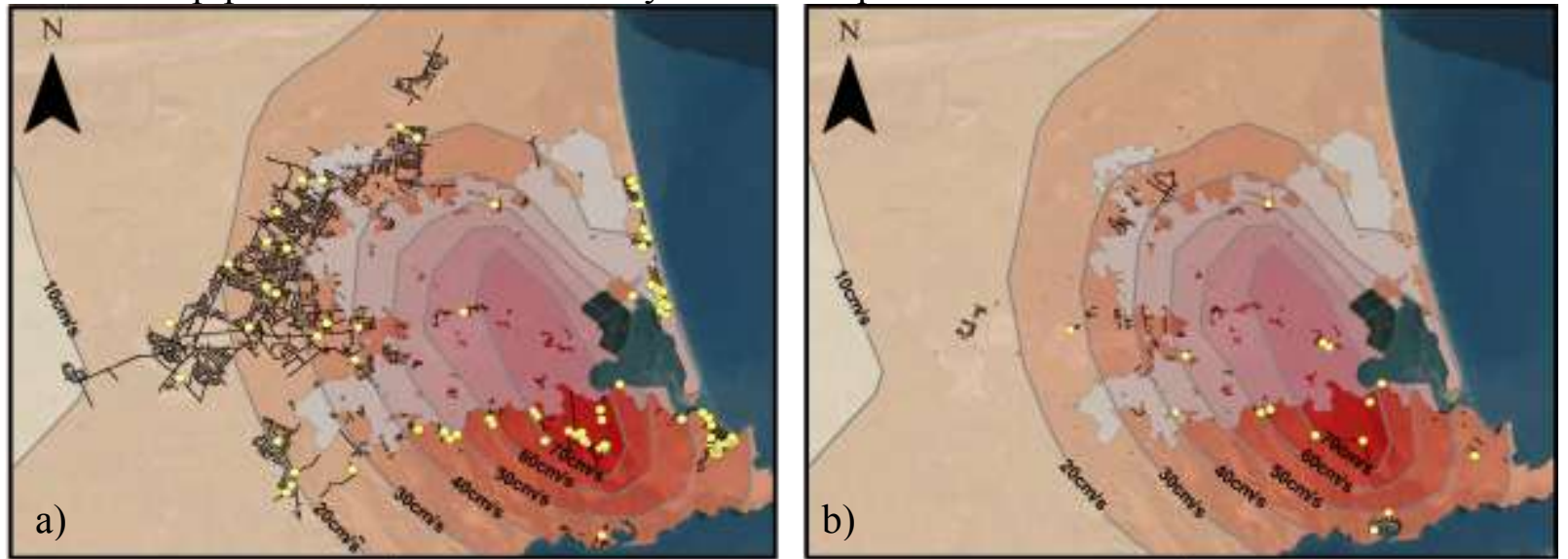

Geometric Mean PGV (cm/sec)
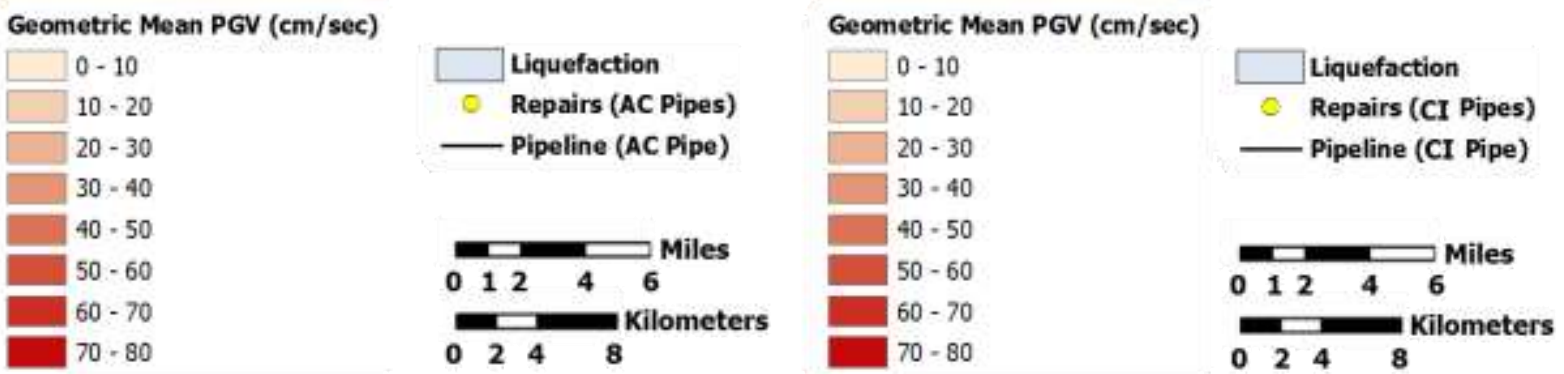

Figure 3. a) 22 Feb. 2011 earthquake map of GMPGV and liquefaction with AC pipelines and repairs, and b) 22 Feb. 2011 earthquake CI pipeline layout, repairs, and map of GMPGV.

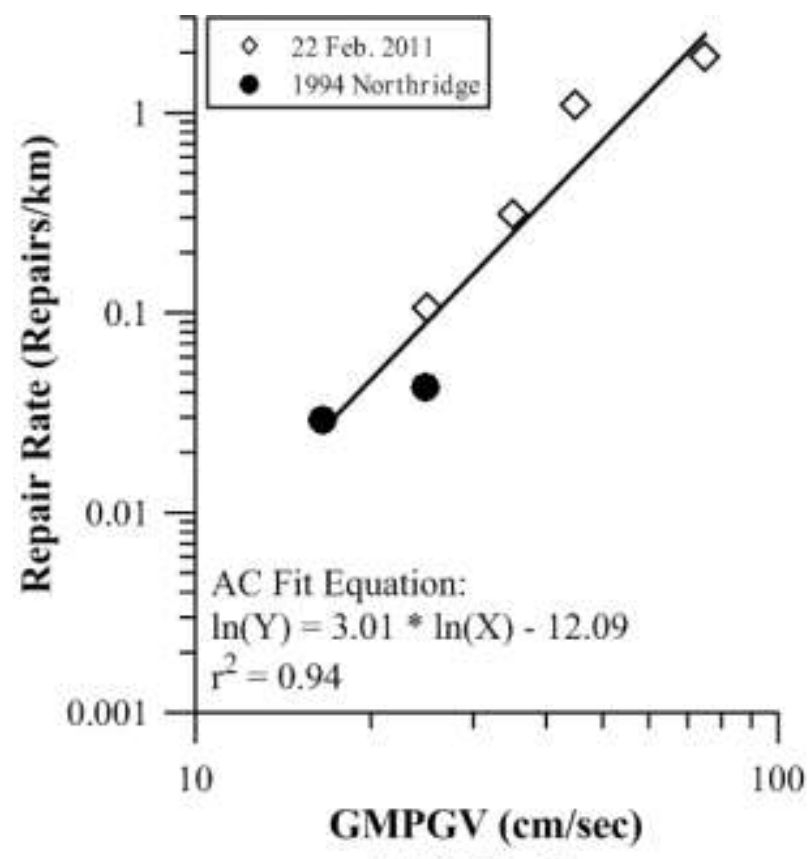

a) AC Pipelines

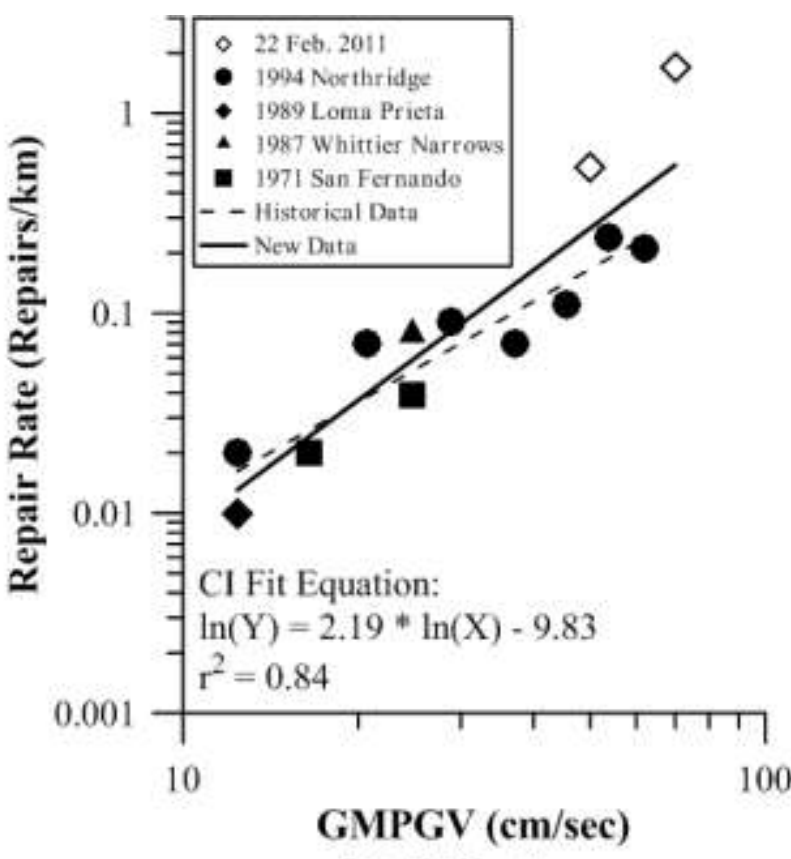

b) CI Pipelines

Figure 4. Repair rate vs. GMPGV for a) AC pipelines and b) CI pipelines. 
reported by Jeon and O'Rourke [9] to develop the linear regression shown in Figure 4b. The linear regressions shown in Figures $4 \mathrm{a}$ and $4 \mathrm{~b}$ combine data points from all earthquakes and provide good fit for the data with relatively high $\mathrm{r}^{2}$ values. Comparison between the regression lines for AC and CI pipelines indicates that AC pipelines sustain up to 3 times more damage due to TGD effects than CI pipelines. The new data points combined with historical data shown in Figures $4 \mathrm{a}$ and $4 \mathrm{~b}$ expand the available database and provide improved regressions for future fragility analyses of water distribution pipeline damage during earthquakes.

\section{RR CORRELATIONS WITH DIFFERENTIAL VERTICAL GROUND MOVEMENT}

Measurements of ground surface elevation before and after each earthquake during the CES were acquired through high resolution Airborne LiDAR surveys by AAM Brisbane (AAM) and New Zealand Aerial Mapping (NZAM) in the Christchurch area. The NZAM LiDAR sets are associated with fundamental vertical accuracy of $\pm 0.10 \mathrm{~m}$ for areas of open ground with hard surfaces which was estimated with respect to field surveying data. The AAM LiDAR sets are associated with a vertical accuracy of \pm 0.07 to $\pm 0.15 \mathrm{~m}$ [10]. The acquired point clouds were classified and screened to develop bare earth digital elevation models (DEM) at $5 \mathrm{~m}$ spacing by averaging ground return elevations with 5-m x 5-m cells. Pairs of the DEMs were used to calculate vertical elevation changes at 5-m spacing for each earthquake as well as for sets of consecutive earthquakes. The data set of vertical elevation changes pertaining to the 22 February 2011 earthquake was obtained through the CERA [15] and was corrected for tectonic movements using a dislocation model of vertical tectonic movements provided by GNS Science.

The differential vertical ground surface movements associated with PGD effects during the 22 February 2011 earthquake were used to calculate angular distortion, $\beta$, and evaluate the effects of differential vertical ground movement on pipeline damage. As discussed by O'Rourke et al. [2], angular distortion is the gradient of settlement between two adjacent LiDAR points

$$
\beta=\frac{\delta z_{1}-\delta z_{2}}{l_{12}}
$$

where $\delta z_{1}$ and $\delta z_{2}$ are the vertical movements of points 1 and 2 , respectively, and $1_{12}$ is the distance between the two points in the horizontal plane.

Angular distortion, $\beta$, is a dimensionless parameter that allows for calculation of relative vertical movement between LiDAR points, eliminating inherent errors in the measurements such as GPS network error and approximations with the reference surface. In this study $\beta$ was calculated on a 5-m grid with a third order finite difference approach that uses a 3-by-3-cell moving window and weighting factors assigned to each neighboring cell based on their distance from the cell at the center of the window [16]. The LiDAR dataset of vertical movement was large, containing approximately 3 million data points in total, and 2.4 million points in the zone of liquefaction effects. The process that was followed to calculate $\beta$ using this dataset was performed within the ArcMap 10.1 [13] environment.

The analytical process for RR correlations with $\beta$ is presented in the flow chart in Figure 5. As 
shown in Figure 5, the "slope" tool was used to calculate $\beta$ using the LiDAR data set of vertical movement in the liquefied zone and the output of the process was a surface of $\beta$ values. Pipelines and repairs inside the area of liquefaction effects were selected using the "clip" tool. Pipelines affected by landslides and rock falls during the 22 Feb. 2011 earthquake were removed from the data set. The selected sets of pipelines and repairs inside the areas of liquefaction effects and at elevation below $50 \mathrm{~m}$ were spatially intersected with the layer of $\beta$ values using the "intersect" tool. RR for a given interval of $\beta$ was calculated by dividing the number of repairs for a particular type of pipeline by the kilometers of that pipeline type within the same interval. The interval size for $\beta$ was $1 \times 10^{-3}$. The calculated RR was associated with the geospatially correlated value of $\beta$ and was used as a single data point in RR correlations.

The screening criteria previously discussed were applied to produce RR vs $\beta$ correlations using appropriate confidence intervals. The confidence level during the screening process was adjusted to account for the number of repairs, which declines progressively for AC, CI, and PVC pipelines. By relaxing the confidence interval in the screening criteria, more RR values are provided to develop a linear regression for each pipe type over a suitable range of $\beta$. Confidence

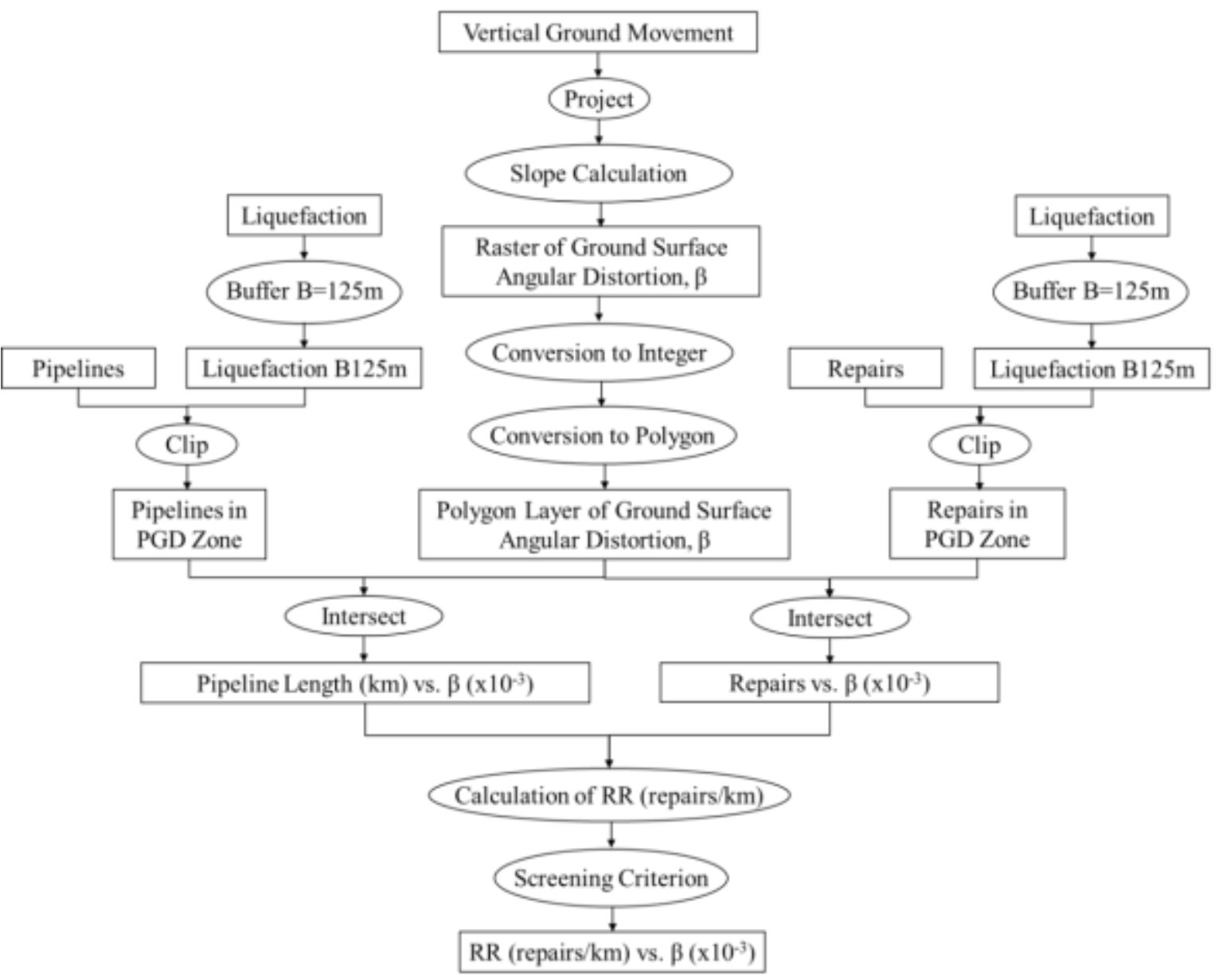

Figure 5. Flow chart for RR correlations with $\beta$ (Rectangles represent input/output data sets and ovals represent processes/tools). 
levels of $95 \%, 90 \%$, and $75 \%$ were used in the screening criteria for $\mathrm{AC}, \mathrm{CI}$, and PVC pipelines, respectively. The results from the regression analysis for $\beta$ are presented in Figure $6 \mathrm{a}$. The linear regressions for all three pipe types provide a good fit of the data with $\mathrm{r}^{2}$ values of $0.86,0.79$, and 0.88 for $\mathrm{AC}, \mathrm{CI}$, and PVC pipelines, respectively. RRs for $\mathrm{AC}$ pipelines plot 1.3 to 2.2 times higher than $\mathrm{CI}$, and 2.1 to 9.9 times higher than PVC. The results indicate that the best performance with respect to $\beta$ is shown by PVC pipelines. Figure $6 \mathrm{~b}$ compares the results of the current investigation, using the most recent and complete repair records, with the results of previous work (O'Rourke et al., 2014). With the exception of a decreased RR for AC pipelines using the new data, the regressions for each pipe type compare favorably with each other.
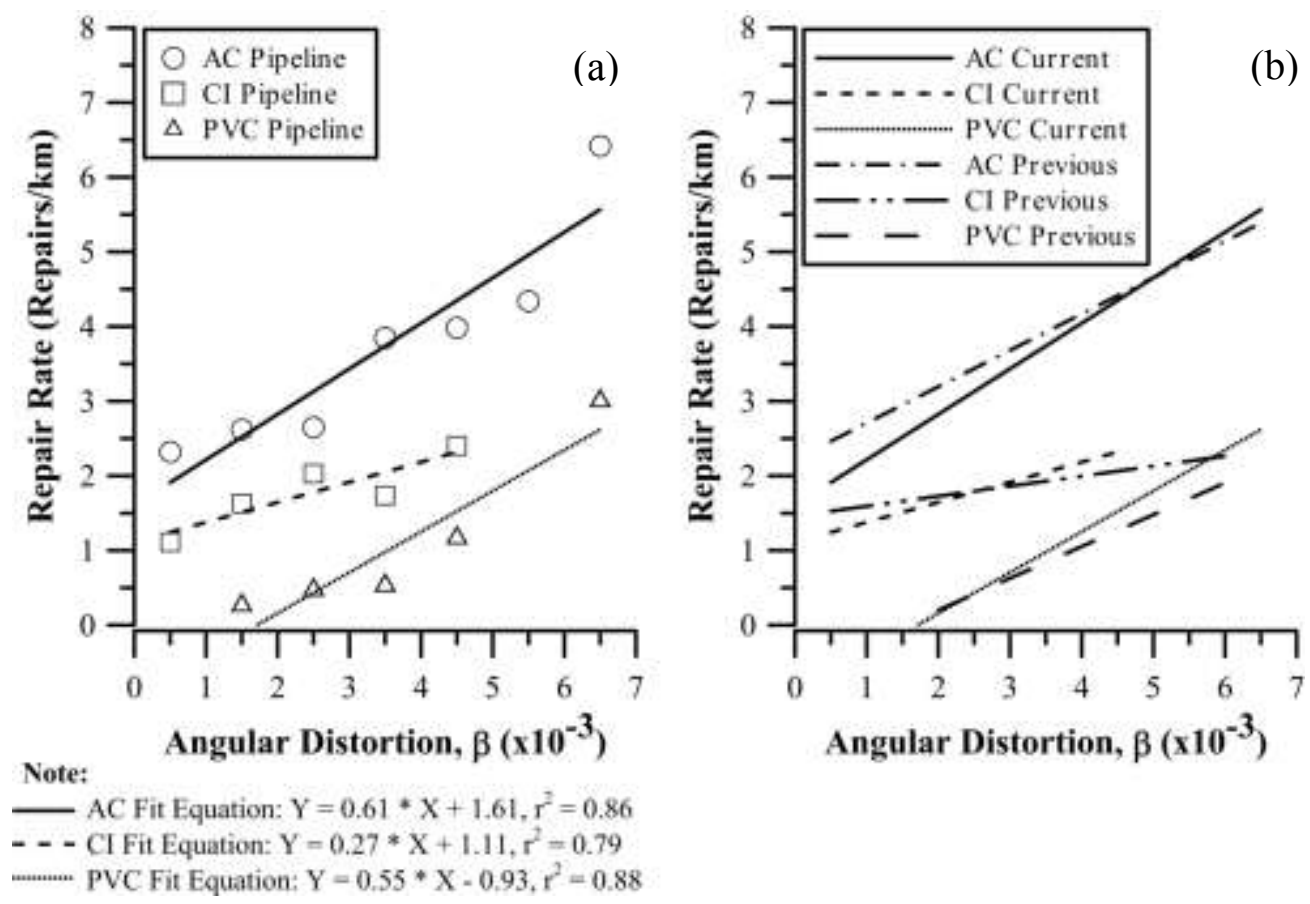

b)

Angular Distortion, $\beta\left(\times 10^{-3}\right)$

Figure 6. Repair rate vs. angular distortion for AC, CI, and PVC pipelines: a) Results with updated measurements, b) Comparison of current and previous results.

\section{RR CORRELATIONS WITH LATERAL GROUND STRAIN}

Similar to vertical ground movements, lateral ground surface movements were calculated both for individual seismic events as well as for sets of consecutive earthquakes using pairs of LiDAR point clouds. The AAM LiDAR horizontal accuracy, compared to land survey measurements supplied by the Christchurch City Council (CCC), Land Information New Zealand (LINZ) and Environment Canterbury, is 40 to $55 \mathrm{~cm}$ [10]. The lateral ground surface movements were calculated using a sub-pixel correlation method developed by Imagin' Labs Corporation, Pasadena, CA, and California Institute of Technology on 4-m spacing (8-m for the preearthquake LiDAR sets) from both ground and non-ground LiDAR points and were subsequently averaged to provide movements in the east-west (EW) and north-south (NS) directions on 56-m spacing. The 4-m and 56-m grids of lateral ground surface movements pertaining to the 22 February 2011 earthquake were provided by Tonkin \& Taylor, New Zealand, and CERA [17], 
respectively, and were corrected for tectonic movements using a dislocation model of horizontal tectonic movements during the 22 February 2011 earthquake provided by GNS Science.

The methodology for calculation of lateral ground strains was based on plane strain conditions for quadrilateral elements and is described in detail by O'Rourke et al. [2]. The lateral ground movement data points were used as corners of square elements, and finite element formulations were used to determine horizontal ground strains in the center of the elements, according to the method described by Cook [18]. Pipeline damage on segmented pipelines, expressed as RR, is assumed to be caused by axial ground strains and related primarily to failure of the joints [19]. The absolute maximum value of lateral ground strain, $\varepsilon_{\mathrm{HP}}$, in each elemental area of ground was used as a metric for RR correlations with lateral ground strain. Lateral ground strain $\varepsilon_{\mathrm{HP}}$ is equal to the absolute maximum value of principal strains given by

$$
\varepsilon_{1,2}=\frac{\varepsilon_{x}+\varepsilon_{y}}{2} \pm \sqrt{\left(\frac{\varepsilon_{x}-\varepsilon_{y}}{2}\right)^{2}+\left(\frac{\gamma_{x y}}{2}\right)^{2}}
$$

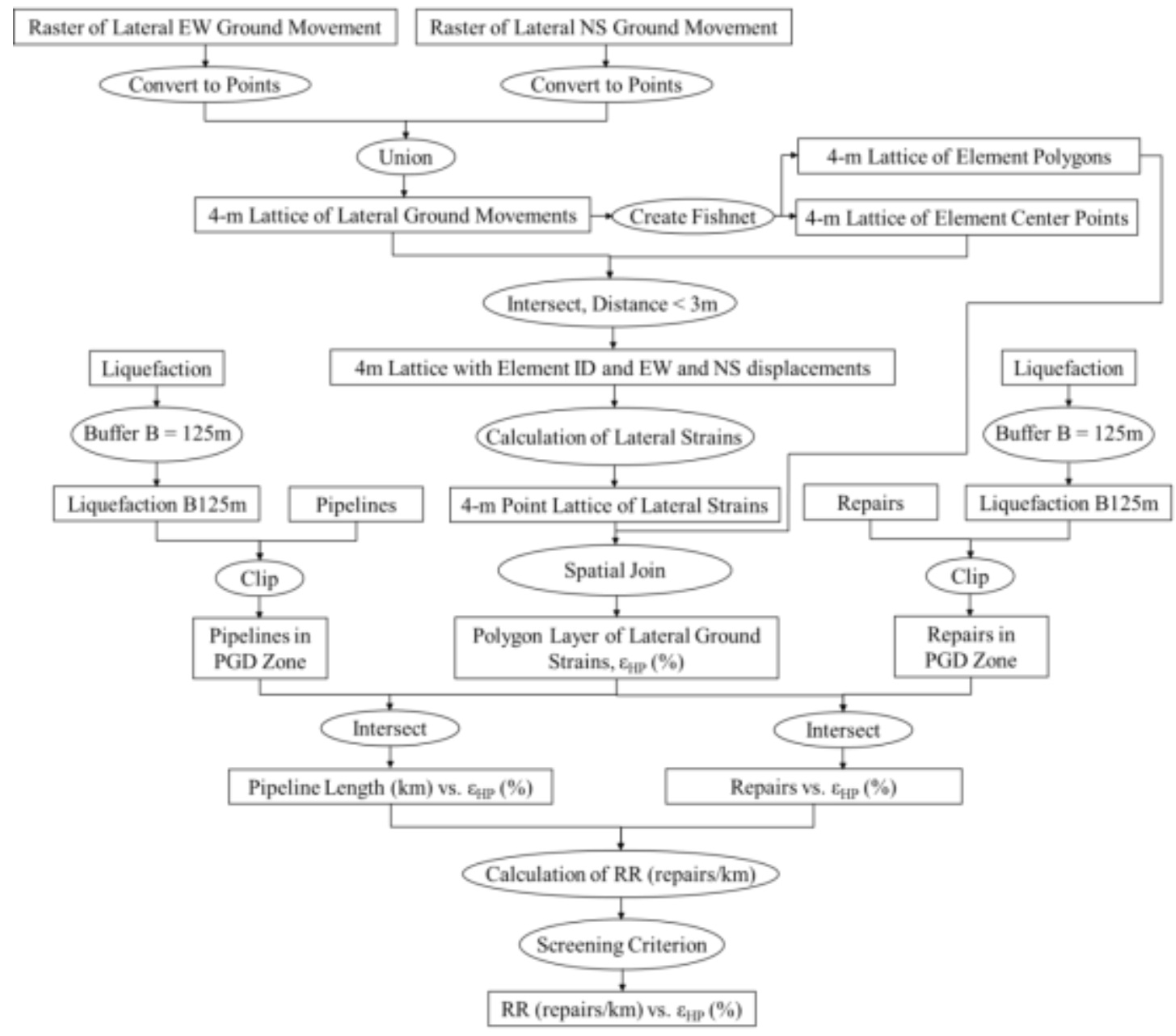

Figure 7. Flow Chart for RR Correlations with $\varepsilon_{H P}$ (Rectangles represent input/output data sets and ovals represent processes/tools). 
The analytical process for RR correlations with $\varepsilon_{\mathrm{HP}}$ is presented in the flow chart in Figure 7. Lateral ground movements in the EW and NS directions at 4-m and 56-m grid spacing were imported in ArcMap 10.1 [13] and were subsequently converted to point layers using the conversion tool. The LiDAR datasets with lateral movements in the EW and NS directions at 4$\mathrm{m}$ grid spacing were large, containing approximately 4.7 million data points in total and 3.7 million points in the zone of observed liquefaction effects. The manipulation of the datasets for calculating lateral ground strains was performed using the Manifold System Release 8 GIS package [20] to overcome memory usage constraints in ArcMap 10.1 [13]. The Matlab and Statistics Toolbox Release 2012a [21] software was used for the calculation of lateral strains.

As previously discussed, the data points of lateral displacement at 4-m and 56-m spacing were considered as corner points of two sets of square quadrilateral elements, and were used to create the 4-m and 56-m grids of quadrilateral elements through the "create fishnet" tool in ArcMap 10.1 [13]. Each element was uniquely identified with an ID in ArcMap 10.1 [13]. The Manifold package [20] was used to correlate each element center point to the appropriate set of four corner points using a structured query language (SQL) statement for each grid size. Spreadsheets of the resulting intersection at 4-m and 56-m spacing were exported to Matlab [21] for calculation of lateral strains. The calculated lateral strains were imported in ArcMap 10.1 [13] in $4 \mathrm{~m} \mathrm{x} 4 \mathrm{~m}$ and $56 \mathrm{~m} \times 56 \mathrm{~m}$ polygons to allow for spatial correlation with the pipeline network and pipe repairs.

Similar to RR correlations with $\beta$, pipelines and repairs inside the areas of liquefaction influence and excluding those above $50 \mathrm{~m}$ in elevation subject to landslides in the Port Hills were used for RR correlations with lateral ground strains at 4-m and 56-m spacing. RR for a given interval of $\varepsilon_{\mathrm{HP}}$ was calculated by dividing the number of repairs for a particular type of pipeline by the kilometers of that pipeline type within the same interval. Pipelines and repairs were initially binned at intervals of $\varepsilon_{\mathrm{HP}}$ equal to $0.05 \%$, and the interval size of $\varepsilon_{\mathrm{HP}}$ was adjusted during the screening process to develop meaningful correlations. The calculated RR was associated with the geospatially corresponding value of $\varepsilon_{\mathrm{HP}}$ and was used as a single data point in RR correlations.

The results for RR correlations with $\varepsilon_{\mathrm{HP}}$ for $\mathrm{AC}, \mathrm{CI}$, and $\mathrm{PVC}$ pipelines are presented in Figure $8 \mathrm{a}$ through Figure 8c. The screening criteria were applied using a confidence level, $\beta_{\mathrm{c}}$, of $95 \%$, $85 \%$, and $75 \%$ for AC, CI, and PVC pipelines, respectively. Procedures similar to those for correlations with angular distortion were used, in which the confidence interval is relaxed for the progressively smaller number of repairs for AC, CI, and PVC. The linear regressions for all three pipe types provide a good fit of the data with relatively high $r^{2}$ values.

Comparison between RR correlations derived from 4-m and 56-m spacing of lateral strain shows significant differences for $\mathrm{AC}$ and $\mathrm{PVC}$ pipelines. For AC pipelines lateral strains at $56-\mathrm{m}$ spacing in Figure 8a correlate with RRs that are 2 to 3 times higher than the RRs for lateral strains at 4-m spacing. Similarly, the PVC pipeline RRs for lateral strains at 56-m spacing in Figure $8 \mathrm{c}$ are up to 2.3 times higher than RRs for lateral strains at 4-m spacing in Figure 8c for the same levels of $\varepsilon_{\mathrm{HP}}$. These differences in RR correlations with $\varepsilon_{\mathrm{HP}}$ between lateral ground strains at 4-m and 56-m spacing reveal the sensitivity of RR correlations to the scale used for discretization of the ground parameters used in the analysis. Lateral movements at 56-m spacing result in a relatively coarse lattice of lateral ground strains that does not capture local effects with high values of horizontal strain. 

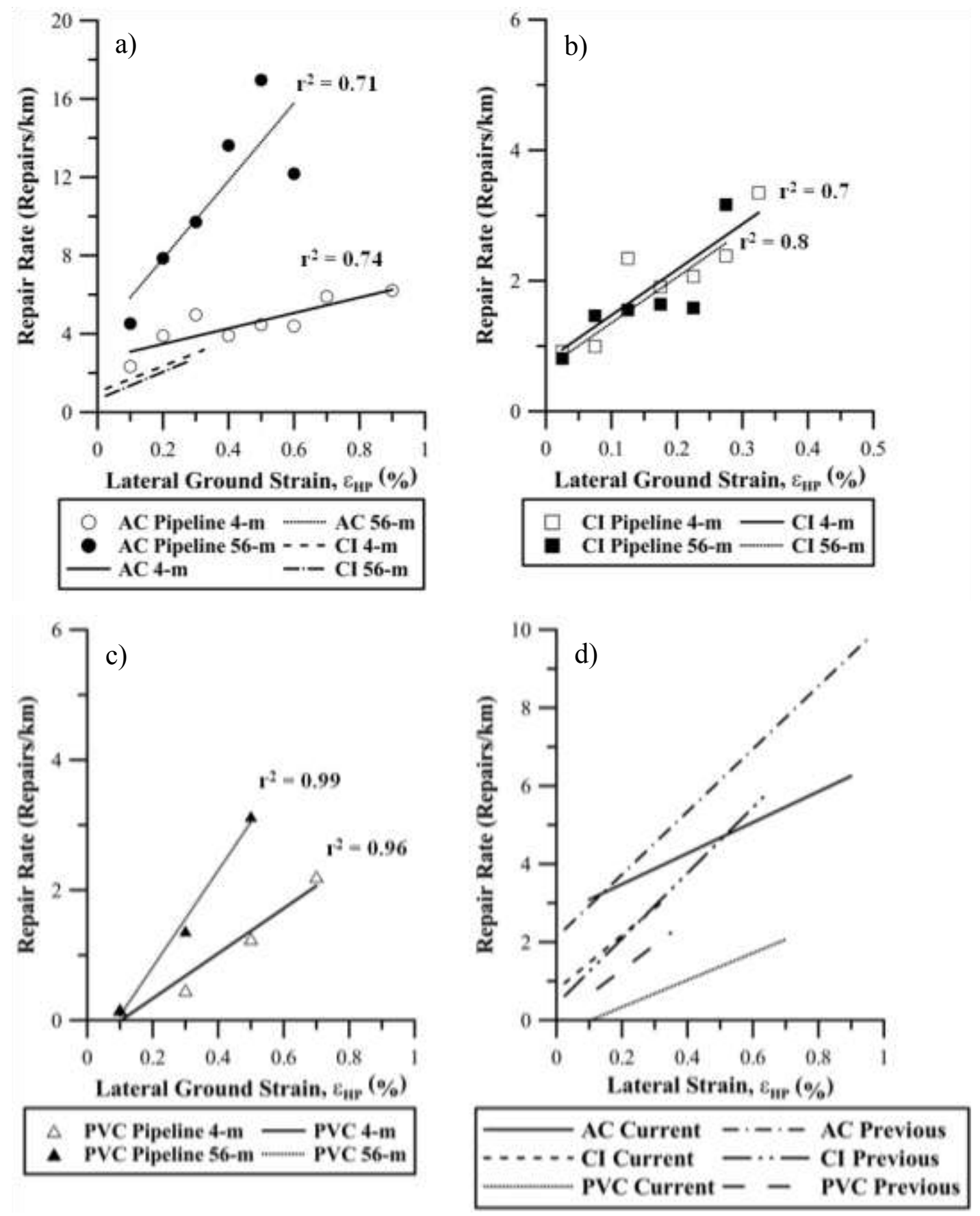

Figure 8. Correlations of repair rate with lateral ground strain at 4-m and 56-m spacing for a) AC, b) CI, and c) PVC pipe materials for the 22 Feb. 2011 earthquake, and d) comparison of repair rate with lateral ground strain at 4-m spacing with previous work by O'Rourke et al. (2014).

In contrast to $\mathrm{AC}$ and PVC pipelines, Figure $8 \mathrm{~b}$ shows that RR correlations for CI pipelines with lateral strains at 56-m and 4-m spacing are in good agreement. CI pipeline repairs are located in areas where more uniform strain patterns take place, whereas $\mathrm{AC}$ and $\mathrm{PVC}$ pipeline repairs are 
located in areas of variable and locally high strains. As a result, higher levels of repair in AC and PVC pipelines are correlated with lower strains using a 56-m spacing which does not capture strain field variability in as much detail as a 4-m spacing. This scaling effect is reflected in the higher regression slopes of RR vs $\varepsilon_{\mathrm{HP}}$ for AC and PVC pipelines. The higher slope occurs because RRs are correlated with $\varepsilon_{\mathrm{HP}}$ that is often too low with a 56-m spacing. In contrast, more uniform strain fields associated with CI pipelines reduce the effects of grid size on the resulting RR vs $\varepsilon_{\mathrm{HP}}$ correlations.

Using the correlations of RR with $\varepsilon_{\mathrm{HP}}$ at 4-m spacing in Figure 8a through Figure 8c, comparison among the results for $\mathrm{AC}, \mathrm{CI}$, and PVC pipelines indicates that $\mathrm{AC}$ pipelines sustained 1.4 to 2.1 times greater damage than the damage observed for CI pipelines. AC pipelines sustained repair rates 2.7 to 10.5 times greater than those of PVC pipelines.

Figure $8 \mathrm{~d}$ compares the results of the current study with the results of previous work by O'Rourke et al. [2] which was performed using a 56-m grid, an earlier formulation of the screening criteria, and an earlier version of the water pipeline repair data set for the 22 February 2011 earthquake. The regressions for AC and PVC pipelines based on 4-m LiDAR spacing plot lower with a reduced regression slope compared to those developed in previous work by O'Rourke et al. [2] with 56-m LiDAR spacing. The regressions for CI pipelines compare favorably because the pipelines were located in relatively uniform strain fields for which the higher resolution at 4-m spacing does not show significant difference compared to 56-m spacing.

\section{COMBINED EFFECTS OF DIFFERENTIAL VERTICAL GROUND MOVEMENT AND LATERAL GROUND STRAIN}

The combined effects of lateral ground strain and vertical differential ground movement on pipeline damage were evaluated using an approach similar to that developed by Boscardin and Cording [22] for ground movement effects on buildings. Pipeline RRs were correlated with both $\beta$ and $\varepsilon_{\mathrm{HP}}$ calculated from vertical and horizontal LiDAR movements at 5-m and 4-m spacing, respectively. Similar correlations were developed by O'Rourke et al. [2] using a 56-m grid, an earlier formulation of the screening criteria, and an earlier version of the water pipeline repair data set for the 22 February 2011 earthquake. It should be pointed out the LiDAR measurements on 5-m and 4-m spacing are well matched with the average length of a jointed pipeline, which is typically $6 \mathrm{~m}$.

Lateral ground strains at 4-m spacing were used to correlate RR with $\varepsilon_{\mathrm{HP}}$. Pipelines and repairs were spatially intersected with $\beta$ and $\varepsilon_{\mathrm{HP}}$, and RR was calculated for a given pair of $\beta$ and $\varepsilon_{\mathrm{HP}}$ intervals by dividing the number of repairs for a particular type of pipeline by the kilometers of that pipeline type within the same pair of intervals. The interval for $\beta$ was $1 \times 10^{-3}$, and for $\varepsilon_{\mathrm{HP}}$ was $0.2 \%$. The RRs were associated with the appropriate pair of $\beta$ and $\varepsilon_{\mathrm{HP}}$ and were used as data points for RR correlations.

The screening criteria in Equation 3 were applied in the data points and resulted in sufficient number of repairs for correlations among $\mathrm{RR}, \beta$, and $\varepsilon_{\mathrm{HP}}$ for $\mathrm{AC}$ and $\mathrm{CI}$ pipelines. There is insufficient number of repairs, however, to develop correlations with PVC pipelines even if the 
confidence interval is relaxed to a relatively low value when screening the data. The confidence level when screening the data for $\mathrm{AC}$ and $\mathrm{CI}$ pipelines was adjusted to $75 \%$ and $60 \%$, respectively, to attain a broad distribution of data within the $\beta$ vs $\varepsilon_{\mathrm{HP}}$ space. Correlations among $\mathrm{RR}, \beta$, and $\varepsilon_{\mathrm{HP}}$ for $\mathrm{AC}$ and $\mathrm{CI}$ pipelines were developed, using the global polynomial interpolation method in ArcMap 10.1 with a first-order polynomial model.

The resulting contour surfaces are presented in Figure $9 \mathrm{a}$ and $9 \mathrm{~b}$ for $\mathrm{AC}$ and CI pipelines, respectively. The extent of the data for CI pipelines is smaller than the extent of data for AC pipelines due to the higher number of AC pipeline repairs that provide a more extensive database for sampling with respect to combined $\varepsilon_{\mathrm{HP}}$ and $\beta$. Similar to Figure 6 and Figure 8 , the results for $\mathrm{AC}$ and $\mathrm{CI}$ pipelines in Figure 9 show that $\mathrm{AC}$ pipelines sustained more damage compared to $\mathrm{CI}$ pipelines.

The correlations in Figure 9 represent a marked improvement over those presented previously by O'Rourke et al. [2], where the interval chosen for $\varepsilon_{\mathrm{HP}}$ was too large. The selection of $\varepsilon_{\mathrm{HP}}$ intervals in Figure 9 was guided by a study of the statistical distribution of lateral ground strains associated with the water pipeline network that is described by Bouziou and O'Rourke [23]. The study shows that approximately $90 \%$ of the $4 \mathrm{~m} \times 4 \mathrm{~m}$ cells of $\varepsilon_{\mathrm{HP}}$ overlying the pipeline network is associated with values of $\varepsilon_{\mathrm{HP}} \leq 1 \%$. Similarly, $90 \%$ of the $5 \mathrm{~m} \times 5 \mathrm{~m}$ cells of $\beta$ overlying the pipeline network is associated with values of $\beta \leq 1 \times 10^{-2}$. Based on these observations, the $\varepsilon_{\mathrm{HP}}$ and $\beta$ intervals in the sampling process were selected to reflect combined $\varepsilon_{\mathrm{HP}}$ and $\beta$ effects at a scale that is consistent with the actual ground deformations experienced by the majority of pipelines.

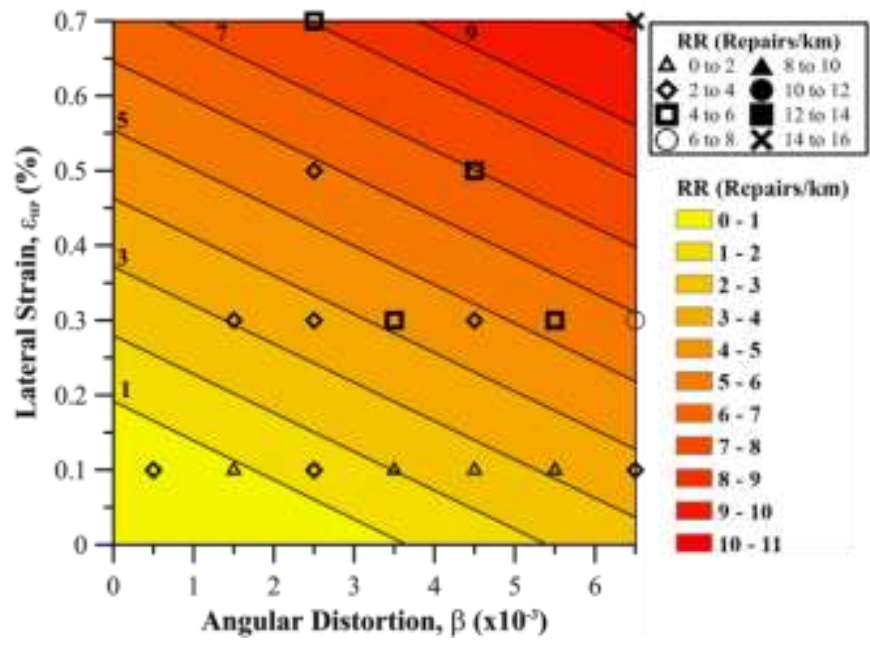

a)

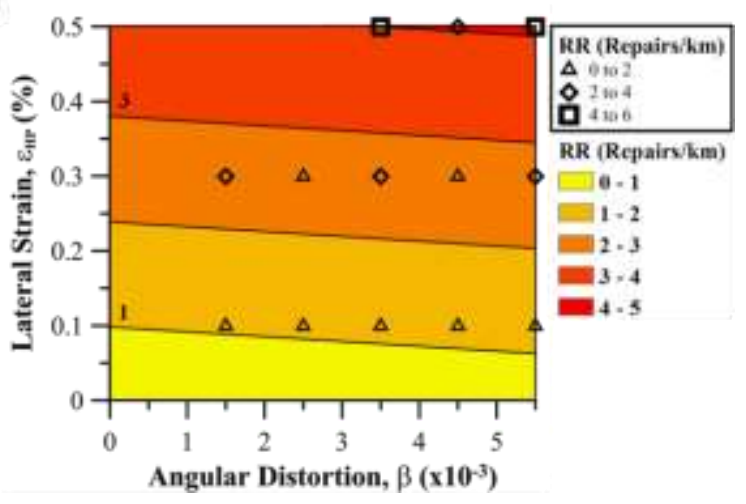

b)

Figure 9. Repair rate vs. lateral ground strain and ground angular distortion for a) AC and b) CI pipelines.

\section{CONCLUSIONS}

The performance of the Christchurch water distribution system is evaluated through spatial 
analysis in this study. This paper expands on work by O'Rourke et al. [2] by using the most recent and complete repair records, incorporating high resolution Light Detection and Ranging (LiDAR) measurements of lateral movements on 4-m spacing, applying refinements for anisotropy in the geo-statistical interpolation of geometric mean peak ground velocity (GMPGV), and using the higher resolution data and improved screening criteria to provide better correlations among pipeline damage and liquefaction-induced lateral ground strains and differential vertical ground movements. The principal findings are:

- The Christchurch data for repair rate (RR) vs GMPGV provide improved regressions for future fragility analyses of water distribution pipeline performance during earthquakes and expand the database of historical data. The regressions in this study compare favorably with those previously reported by O'Rourke et al. [2].

- In this study, the regressions between RR and ground angular distortion, $\beta$, show a slightly lower level of damage for $\mathrm{AC}$ pipelines at relatively small $\beta$ compared to the regressions reported by O'Rourke et al. [2], but otherwise for AC, CI, and PVC pipelines compare favorably with the previous work. In the present study, RRs vs $\beta$ for AC pipelines plot approximately two times higher than those for CI pipelines, and 5 to 10 times higher than those for PVC pipelines.

- The regressions between $\mathrm{RR}$ and lateral ground strain, $\varepsilon_{\mathrm{HP}}$, using the 4-m LiDAR measurement spacing are significantly different for $\mathrm{AC}$ and $\mathrm{PVC}$ pipelines than those previously reported for LiDAR measurements on $56-\mathrm{m}$ spacing. The RR vs $\varepsilon_{\mathrm{HP}}$ regressions for CI pipelines compare favorably because the pipelines were located in relatively uniform strain fields for which there is no significant difference between 4-m and 56-m resolution. RRs vs $\varepsilon_{\mathrm{HP}}$ for $\mathrm{AC}$ pipelines are approximately $50 \%$ to $100 \%$ higher than those for CI pipelines, and approximately 3 to 11 times higher than those for PVC pipelines.

- The correlations among RR, $\varepsilon_{\mathrm{HP}}$, and $\beta$ for $\mathrm{AC}$ and $\mathrm{CI}$ pipelines in this work are a significant improvement over those previously presented by O'Rourke et al. [2]. These correlations provide the means to predict RR with respect to the combined effects of lateral ground strain and differential vertical ground movement.

The segmented pipelines most resilient to permanent and transient (PGD and TGD, respectively) ground deformation effects are PVC pipelines, for which substantial improvements in earthquake performance are quantified in this work with respect to $\mathrm{AC}$ and $\mathrm{CI}$ pipelines.

Scale effects have a substantial impact on the inferred relationship between pipeline damage and lateral ground strain, and depend on local variations in the strain field. High resolution data are needed to capture the influence of localized ground deformation. Computational modeling that utilizes regressions, such as those of RR vs $\varepsilon_{\mathrm{HP}}$, need to account for scale effects, and should strive for the highest resolution possible at a scale equivalent to that of the structure being investigated.

Correlations among pipeline repair rates (RR), lateral ground strains, and differential vertical ground surface movements provide the means to predict pipeline damage on the basis of the combined effects of lateral ground strain and differential vertical ground movement. These correlations may be used in future planning, design, and loss estimation to assess limiting deformations for pipelines subjected to both PGD-induced lateral and vertical differential 
displacements.

The flow charts with detailed steps in the geospatial analysis that were presented in this paper provide detailed documentation of the methods used for analyzing the data for clarity of process and to assist in future investigations with data of similar size and complexity.

\section{ACKNOWLEDGEMENTS}

The work described in this paper was supported by the National Science Foundation (NSF) under Award No. 1137977 and the U.S. Geological Survey (USGS) under Grant No. G12AP20034. Thanks are extended to the Christchurch Earthquake Recovery Authority (CERA), Stronger Christchurch Infrastructure Rebuild Team (SCIRT), Christchurch City Council (CCC), Earthquake Commission (EQC), and Tonkin and Taylor Ltd (T\&T) for their assistance. Special thanks are extended to Hugh Cowan of EQC, John Noonan of SCIRT, and Sjoerd van Ballegooy and Bruce Deam of T\&T. All LiDAR survey and liquefaction observation data are available through the CERA [3] and were provided courtesy of EQC.

\section{REFERENCES}

[1] Cubrinovski M, Hughes M, Bradley B, McCahon I, McDonald Y, Simpson H, Cameron R, Christison M, Henderson B, Orense R. O'Rourke T. Liquefaction Impacts on Pipe Networks: Short Term Recovery Project No. 6. Natural Hazards Research Platform, University of Canterbury, 2011; p.149. http://hdl.handle.net/10092/10178

[2] O'Rourke TD, Jeon S-S, Toprak S, Cubrinovski M, Hughes M, van Ballegooy M, Bouziou D. Earthquake response of underground pipeline networks in Christchurch, NZ. $\begin{array}{llll}\text { Earthquake } & \text { Spectra } & \text { 30(1):183-204. } & \text { DOI: }\end{array}$ http://dx.doi.org/10.1193/030413EQS062M

[3] Canterbury Earthquake Recovery Authority (CERA). Geotechnical database for Canterbury Earthquake Sequence, NZ https://canterburygeotechnicaldatabase.projectorbit.com. [August 2012]

[4] Cubrinovski M, Hughes M, Bradley B, Noonan J, Hopkins R, McNeill S, English G. Performance of horizontal infrastructure in Christchurch City through the 2010-2011 Canterbury Earthquake Sequence. Civil \& Natural Resources Engineering: Research Report 2014-02, University of Canterbury, March 2014: p. 129.

[5] Canterbury Geotechnical Database. Liquefaction interpreted from aerial photography, map layer CGD0200 - 11 Feb 2013. https://canterburygeotechnicaldatabase.projectorbit.com/. [August 2012] 
[6] O'Rourke MJ, Liu X. Response of buried pipelines subject to earthquake effects. Monograph No.3: Multidisciplinary Center for Earthquake Engineering Research, Buffalo, NY, 1999. http://hdl.handle.net/10477/588

[7] O'Rourke T.D., Jeon S-S., Toprak S., Cubrinovski M, Jung JK. Underground lifeline system performance during the Canterbury Earthquake Sequence. Proceedings of the 15th world conference on earthquake engineering, Lisbon, Portugal, 2012: p.24.

[8] Geonet. Processed strong ground motions. ftp://ftp.geonet.org.nz/strong/processed/Proc/2011/. [June 2013]

[9] Jeon S-S., O'Rourke T.D. Northridge earthquake effects on pipelines and residential buildings. Bulletin of the Seismological Society of America 2005; 95(1): 294-318. DOI: 10.1785/0120040020

[10] Beavan J, Levick S, Lee J, Jones K. Ground displacements and dilatational strains caused by the 2010-2011 Canterbury earthquakes. GNS Science Consultancy Report 2012; 67:59.

[11] O'Rourke MJ, Deyoe E. Seismic damage to segmented buried pipe. Earthquake Spectra 2004; 20(4):1167-1183. DOI: http://dx.doi.org/10.1193/1.1808143

[12] Bradley BA, Cubrinovski M. Near-source strong ground motions observed in the 22 February 2011 Christchurch earthquake. Seismological Research Letters 2011; 82(6):85365. DOI: $10.1785 / \mathrm{gssrl} .82 .6 .853$

[13] ArcMap 10.1. Environmental Systems Resource Institute (ESRI): Redlands, California, 2012.

[14] Jeon S-S. Earthquake performance of pipelines and residential buildings and rehabilitation with cast-in-place pipe lining systems. Ph.D. Dissertation: Cornell University, Ithaca, NY, 2002.

[15] Canterbury Geotechnical Database. LiDAR and digital elevation models, map layer CGD0500 - 23 July 2012. https://canterburygeotechnicaldatabase.projectorbit.com/. [August 2012]

[16] Burrough PA, McDonell RA. Principles of geographical information systems. Oxford University Press: New York, NY, 1998; p. 190.

[17] Canterbury Geotechnical Database. Horizontal ground movements, map layer CGD0700 23 July 2012. https://canterburygeotechnicaldatabase.projectorbit.com/. [August 2012]

[18] Cook RD. Finite element modeling for stress analysis. John Wiley and Sons: New York, NY, 1995.

[19] O'Rourke MJ, Liu JX. Seismic design of buried and offshore pipelines. Monograph No. 4: Multidisciplinary Center for Earthquake Engineering Research, Buffalo, NY, 2012.

[20] Manifold System Release 8. Manifold Software Limited: Wanchai, Hong Kong, 2013. 
[21] MATLAB and Statistics Toolbox Release 2012a. The MathWorks, Inc.: Natick, Massachusetts, US, 2012.

[22] Boscardin MD, Cording, EJ. Building response to excavation-induced settlement. Journal of Geotechnical Engineering 1989; 115(1):1-21. DOI: 10.1061/(ASCE)07339410(1989)115:1(1)

[23] Bouziou D, O'Rourke TD, Cubrinovski M, Henderson D. Evaluation of Ground Deformations during the 2010-2011 Canterbury Earthquake Sequence. $6^{\text {th }}$ International Conference on Earthquake Geotechnical Engineering, Christchurch, New Zealand, November 1-4, 2015, Paper No. 423. 